\section{Kidney \\ Blood Pressure Research}

Review

\title{
What Would You Like to Eat, Mr CKD Microbiota? A Mediterranean Diet, please!
}

\author{
Eustacchio Montemurno ${ }^{a}$ Carmela Cosola $^{b} \quad$ Giuseppe Dalfino ${ }^{b}$ \\ Giuseppe Daidonec Maria De Angelis ${ }^{d}$ Marco Gobbettid ${ }^{d}$ Loreto Gesualdo ${ }^{a}$
}

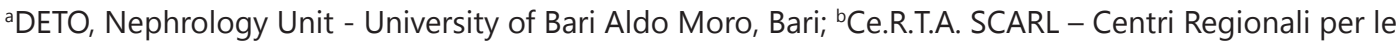
Tecnologie Agroalimentari, Foggia; 'Renal and Dialysis Unit, Umberto I Hospital, Siracusa; ${ }^{\mathrm{d} D e p a r t m e n t}$ of Soil, Plant and Food Sciences, University of Bari Aldo Moro, Bari, Italy

\section{Key Words}

Mediterranean Diet $•$ Gut Microbiota $•$ Chronic Kidney Disease $\cdot$ Western Diet

\begin{abstract}
In this review we elucidate the role of gut microbiota as the plausible missing link between food and health, focusing on chronic kidney disease (CKD). Microbiota, the microbial community harboured in the large intestine, is considered a symbiotic "supplementary organ". It contributes to digestion, mainly through two catabolic pathways: saccharolytic (fermentation) or proteolytic (putrefaction). It also interacts with host influencing immunity, metabolism, and health status. It is believed that a balanced healthy microbiota is primarily saccharolytic and diet has a deep effect on its composition. Mediterranean Diet, UNESCO "Intangible Cultural Heritage of Humanity", prevents cardiovascular and metabolic systemic diseases, thanks to the high supply of fibres and antioxidants. Mediterranean Diet also favours the prevalence of saccharolytic species, while Western Diet promotes the shift towards a proteolytic profile (dysbiosis). Emerging evidences highlight the association between a wide range of diseases and dysbiosis. In CKD a vicious circle exists, in which proteolytic-derived microbial metabolites ( $p$-cresol and indoxyl sulphate), represent the main circulating uremic toxins: their accumulation worsens dysbiosis and promotes CKD progression. Gut microbiota shaping through nonpharmacologic nutritional treatments, based on Mediterranean Diet, represents an innovative approach in CKD, potentially restoring microbiota balance, ameliorating CKD conditions and slowing down disease progression.
\end{abstract}

E. Montemurnoa and C. Cosolab contributed equally to this work. 


\section{Kidney Blood Pressure Research}

Kidney Blood Press Res 2014;39:114-123

\begin{tabular}{l|l}
\hline DOI: $10.1159 / 000355785$ & C 2014 S. Karger AG, Basel
\end{tabular}

Published onlıne: July 29, 2014

www.karger.com/kbr

Montemurno et al.: What Would You Like to Eat, Mr CKD Microbiota? A Mediterranean Diet, please!

\section{The Mediterranean Diet: the perfect prevention for a wide range of diseases}

In 406 B.C., Hippocrates, the father of medicine, stated: "Let food be your medicine and medicine be your food". Twenty centuries after, the Mediterranean Diet was inscribed in 2013 on the Representative List of the Intangible Cultural Heritage of Humanity (http:// www.unesco.org/culture/ich/RL/00884).

The proof of the indissoluble link between diet and health, advocated by Hippocrates in ancient times, comes from the current, striking evidence in literature that specific dietary patterns are able to modulate risk factors of cardiovascular and systemic diseases, such as diabetes, hypertension and hyperlipidemia [1] .

Moreover, it is well assessed in literature that adherence to the Mediterranean Diet leads to a decrease in all the causes of mortality and in the incidence of cardiovascular diseases [2].

The Mediterranean Diet is based on a considerable consumption of carbohydrates, primarily unrefined grains, high quantities of fruits and vegetables, matched with legumes, nuts, olive oil, fish and a moderate consumption of red wine (containing antioxidants with a protective action); the use of dairy products and red meats is low [3, 4].

Interestingly, although protective against cardiovascular diseases, the Mediterranean Diet includes a relatively high-fat consumption, mostly based on olive oil, used to cook and dress salads. This paradox can be explained by the association, found in extra-virgin olive oil, between oleic acid and a high content of polyphenols, which confer anti-oxidant, anti-inflammatory and anti-microbial properties to this extraordinary and tasty pillar of the Mediterranean Diet [4]: some authors hypothesize that these anti-atherosclerotic properties of olive oil may induce a reduction in endothelial damage and may improve the regenerative capacity of the endothelium [5].

An increasing body of evidence shows the existence of an inverse relationship between the consumption of fiber-rich foods, such as fruits, vegetables and legumes, and the incidence of cardiovascular and metabolic diseases [6]. These protective factors (fibres, antioxidants, folate and vitamins) are well represented in Mediterranean Diet, which is by now acknowledged as an irreplaceable part of a healthy lifestyle.

Indeed, with its richness in antioxidant molecules (found in fruits, vegetables, and red wine), the suppression of lipoprotein peroxidation, the reduction of endothelial and monocytary adhesion molecules and chemokines and its anti-inflammatory properties, the Mediterranean Diet plays an effective role in the prevention of systemic diseases, mainly cardiovascular diseases [7].

Given that the Mediterranean Diet and its high content in fibres are highly beneficial, what is the missing link between food and health?

\section{The Gut Microbiota: is it the missing link?}

The large intestine, beyond performing different physiological functions in digestion, such as salt and water absorption, harbours a large and complex microbial community termed gut microflora or microbiota. Far from merely supporting host digestive processes, this symbiotic "supplementary organ" is biochemically very active with a metabolic activity, secondary only to the liver, and interacting with its host.

It exerts fundamental influence on local and systemic processes, such as immunity, metabolism, having a deep influence on the general health status [8]. The whole microbial genome of the gut microbiota is called gut microbiome [9], which is 100 times greater than human genome [10].

Overall, human microbiota contains ca. 1014 bacterial cells, a number that is 10 times higher than the number of human body cells [11]. The human intestine is particularly dense of microbes, about 1012 bacteria per gram (dry weight), especially at colon level [12]. Colonic bacteria species participate in food digestion through two main catabolic pathway 


\section{Kidney Blood Pressure Research}

Kidney Blood Press Res 2014;39:114-123

\begin{tabular}{l|l}
\hline DOI: $10.1159 / 000355785$ & C 2014 S. Karger AG, Basel
\end{tabular}

Published onlıne: July 29, 2014

www.karger.com/kbr

Montemurno et al.: What Would You Like to Eat, Mr CKD Microbiota? A Mediterranean Diet, please!

that could be categorized as saccharolytic (i.e., involving bacteria dominantly fermenting carbohydrates) or proteolytic (i.e., in which bacterial species are predominantly protein fermenters).

It is generally agreed that a healthy, balanced colonic microbiota is primarily saccharolytic and sees the prevalence of Bifidobacteria and Lactobacilli. These bacteria hydrolyze complex polysaccharides in monomeric sugars by their membranous or extra-cellular enzymes; sugars are then converted in short-chain fatty acids (SCFA), mainly acetate, propionate and butyrate [13]. SCFA are known to exert a protective action and a positive immune-modulating activity [14], guaranteeing a general healthy status.

The second catabolic pathway is represented by protein fermentation (putrefaction), which leads to a variety of end-products including short or branched-chain fatty acids, and other co-metabolites such as ammonia, amines, thiols, phenols, and indoles, some of which are potentially toxic and are considerate microbial uremic toxins [15]. Indeed, some species within Clostridium, Bacteroides, Enterobacterium, Bifidobacterium and Lactobacillus [1618] metabolize aromatic amino acids to phenolic compounds: tyrosine yields phenol and p-cresol which circulates in blood as its sulphate conjugate, $\mathrm{p}$-cresyl sulphate, while phenylalanine is converted into indoxyl sulphate.

Gut microbiota plays a role in metabolic processes and strongly affects general health status. On the other hand, it is correlated also with systemic and metabolic disorders, such as obesity and its comorbidities (insulin resistance, diabetes and cardiovascular disease) [19].

Interestingly, the symbiotic relationship between microbiota and the human being is supported by the existence of a bidirectional communication between gut microbiota and organs based on a "social network model". This dual exchange of both hormonal and neurotransmitted signals operates in healthy conditions and obviously plays a fundamental role in pathologic contexts [20].

On the basis of the evidence in literature, gut microbiota can be considered one eligible candidate for the missing link between diet and health: beyond its role in metabolism, immunity and digestion, a variety of studies has demonstrated that the microbiota composition is aberrant in humans diagnosed with chronic intestinal or systemic diseases associated with the Western lifestyle [21].

\section{The Mediterranean Diet as a beneficial modulator of gut microbiota}

It is important to specify that the microbiota composition is a highly personalized, "fingerprint-like" peculiarity of each individual. In addition, high-throughput technologies applied to gut microbiota studies have allowed defining high-level bacteria clusters, called "enterotypes", which are relatively stable in time and, interestingly, are associated with different long-term dietary patterns $[22,23]$. For example, a study showed that Bacteroides enterotypes are associated with animal fat and protein dietary patterns, while Prevotella correlates with carbohydrates patterns [24].

The reason for this association is likely due to a priceless-value feature of the human gut microbiota, namely its plasticity: in fact, microbiota composition is strictly dependent on diet.

A recent research revealed a high level of variability in microbiota, significantly correlated with dietary habits: microbiota analyses of vegans, vegetarians and omnivores showed differences in taxonomic composition [25], confirming the shaping effect of long-term dietary patterns on gut microflora.

Not only long-term dietary habits, but also short-term food intake seems to influence microbiota relative abundance and, above all, microbial transcriptional response. A recent interesting study showed that even a short-term diet of five days is able to modify microbiota community, promoting the shift of relative microbiota population abundance in response to a plant-based or an animal-based diet. In particular, the latter has a greater impact on 


\section{Kidney Blood Pressure Research}

Kidney Blood Press Res 2014;39:114-123

\begin{tabular}{l|l}
\hline DOI: 10.1159/000355785 & (C) 2014 S. Karger AG, Basel
\end{tabular}

Publisned ontIne: Jury 29, 2014

www.karger.com/kbr

Montemurno et al.: What Would You Like to Eat, Mr CKD Microbiota? A Mediterranean Diet, please!

gut microbiota than a plant-based diet, acting as a selective pressure agent that favours the selection of bile-resistant taxa and the shift from saccharolytic fermentation to proteolytic processes [26]. But, more generally, the diet induces rapid, selective and specific adaptations both to regulatory gene expression and at taxonomic level. Interestingly, the diet strongly affects human gut microbiome, independently from the pre-existing microbiota taxonomic individual differences, inducing specific expression patterns in response to plant or animal food. From an evolutionary point of view, the ability of the global transcriptional response to rapidly adapt to a saccharolytic or a proteolytic response could represent the evolutionary heritage of human nutrition, used to switch between herbivorous and carnivorous feeding, in adaptation to the different availability of vegetable or animal food sources, as postulated by the authors [26, 27].

Given this evidence in literature, one can reasonably infer that the Mediterranean Diet, rich in complex carbohydrates, fibres, vitamins and poor in animal proteins and fats, is able to promote the beneficial shift to a saccharolytic profile, acting as a selector of "positive" microbes that, in turn, favour and promote a general healthy status. Indeed, short-chain fatty acids (SCFA), produced by complex carbohydrates fermentation, show an immune-modulating activity, either by promoting intestinal barrier integrity (which becomes a protective factor by avoiding the contact of luminal bacteria with intestinal immune system and the transit of inflammation-inducing bacterial antigens) and by eliciting direct transcriptional responses in immunity cells [14].

To the contrary, a Western-style diet, rich in animal proteins and fats, by means of an increased bile salts secretion, has a selective effect on bile-resistant and sulphate-reducing bacteria, with a proteolytic and putrefactive action. Moreover, proteolytic bacteria metabolites, such as hydrogen sulphide and secondary bile acids, are believed to promote the onset of "Western diseases", such as colon cancer and chronic systemic disorders [28].

\section{Gut Microbiota interacting with Chronic Kidney Disease}

Chronic kidney disease (CKD) is a worldwide public health problem, with an increased incidence in the last years [29].

CKD is strictly associated with the incidence of cardiovascular disease (CVD); in this setting, multiple risk factors, such as diabetes, hypertension, obesity, dyslipidemia, inflammation, oxidative stress and malnutrition, contribute to kidney disease progression [30, 31].

Recent studies showed a fundamental role of nutritional management in CKD. After all, it is well established that some dietary patterns, like the Mediterranean Diet, play a protective role by controlling cardiovascular risk factors [1].

The effect of nutrition, based on the principles of the Mediterranean Diet, was evaluated by Khedidja Mekki et al. in a group of non-dialysis CKD patients. Their results showed a positive effect on renal function, as reported by a stable Glomerular Filtration Rate [2].

In this context, an active involvement of gut microbiota in the onset and/or in the progression of kidney disease is conceivable.

A recent and elegant demonstration of this hypothesis comes from a study showing that TNF family members B cell activation factor (BAFF) signalling is implicated in the pathogenesis of Immunoglobuline-A Nephropathy (IgAN). In the presence of excess BAFF, as in BAFF$\mathrm{Tg}$ mice, some B cell subsets expand abnormally and B cell tolerance to self-antigen is perturbed. These mice develop an IgA-driven nephritis: the development of this condition, which is commensal microbiota-dependent, involves a breakdown in the normal barrier between the mucosal and peripheral compartments [32].

Consistently, our research group recently studied faecal microbiota from a population of IgAN patients, comparing it with healthy subjects: we found both a reduced diversity and an induced dysbiosis in IgAN patients compared with controls (Unpublished data).

As evidenced in other gastrointestinal and systemic diseases [33], also in CKD a gut microbiota dysbiosis is present. For instance, Vaziri ND et al. showed that certain families in 


\section{Kidney Blood Pressure Research}

Kidney Blood Press Res 2014;39:114-123

DOI: 10.1159/000355785
Publisned onIIne: July 29,2014

(c) 2014 S. Karger AG, Basel

www.karger.com/kbr

Montemurno et al.: What Would You Like to Eat, Mr CKD Microbiota? A Mediterranean Diet, please!

the Bacteroidetes and Firmicutes were less prevalent in the uremic rats, especially in Lactobacillaceae and Prevotellaceae species [34] .

On the other hand, it has been demonstrated that in CKD patients a compensatory mechanism occurs, as a consequence of nephrons failure. This mechanism, aimed at the elimination of waste products and the preservation of electrolytes, involves the colon as a replacement excretion system. A massive urea discharge and uric acid and oxalate epithelial secretion occurs [34], altering colonic microenvironment and subsequently affecting the gut microbial population [35].

In addition to microbiota modelling in CKD, other studies have reported that hemodialysis patients, as compared with control subjects, have a significantly minor dietary fibres intake, an important source of fermentable carbohydrates in the colon [36]. Moreover, in these patients, an altered protein assimilation in the small intestine, with the consequent increase in abundance of dietary protein bio-availability in the colon has been observed. This leads to a decreased amount of available carbohydrate in the large intestine, favouring a switch from a saccharolytic to a proteolytic catabolism. In this context, bacteria hydrolyze urea, carrying to high ammonia concentration and alkaline $\mathrm{pH}$, which in turn favours proteolytic species proliferation [37].

Protein fermentation leads to the generation of different waste metabolites, such as phenols and indoles, mainly represented by p-cresol and indoxyl sulphate, which are known as the main uremic toxins found in CKD patients and promoting disease progression. In fact, the administration of indoxyl sulphate in uremic rats induced the renal expression of genes related to tubulointerstitial fibrosis, such as TGF-beta 1, tissue inhibitor of metalloproteinase, and pro-alpha 1 collagen [38].

Besides being involved in merely metabolic processes in health and disease, microbiota could also explain inflammatory and oxidative co-morbidities found in CKD.

Uremia per se alters the intestinal barrier integrity, inducing an increase in intestinal permeability, probably by colonic epithelial tight-junction disruption [27]. The increased intestinal permeability allows bacterial translocation, which is responsible for endotoxemia. In detail, endotoxin is a potent immune system activator which induces the inflammatory cascade and leads to systemic, low-grade inflammation.

\section{Future perspectives: lessons from Hippocrates}

The emerging concept regarding the relationship among food, microbiota and health is the existence of "modifiable risk factors" which are strictly dependent on diet.

Accumulating evidence indicates that a highly diverse microbiota is associated to general healthy conditions, promoting resilience and homeostasis [8]. On the other hand, different factors, primarily diet but also antibiotics and lifestyle, acting as perturbing factors, may induce a dysbiosis status which, in turn, is correlated with a number of pathologies, ranging from metabolic to immunologic and psychic diseases [20,33].

Given microbiota plasticity, it is arguable that dietary interventions could positively affect health status, either by keeping a physiological gut flora or by helping to reverse a dysbiosis situation: gut microbiota may be considered as a novel and holistic target for non-pharmacologic treatments in a variety of pathological settings.

In the context of microbiota-pathology connection, chronic kidney disease deserves a special mention. As already stated, it is known that some bacterial metabolic products, such as p-cresol and indoxyl sulphate, are the main uremic toxins: notoriously, the price to pay for the symbiotic relationship between humans and microbiota is the need for human excretion system to deal with microbial waste, and this becomes critical when kidney function is impaired [15].

The possibility of acting directly on gut microbiota in order to improve uremic toxins accumulation has been explored in a number of studies [39]: currently, many efforts are directed towards the modulation of colonic microenvironment and bacterial growth, sub- 


\section{Kidney Blood Pressure Research}

Kidney Blood Press Res 2014;39:114-123

\begin{tabular}{l|l}
\hline DOI: 10.1159/000355785 & (C) 2014 S. Karger AG, Basel
\end{tabular}

Published onlıne: July 29, 2014

www.karger.com/kbr

Diet, please!

sequently blocking LPS and attenuating systemic inflammation, or in limiting intestinal absorption of microbial derived uremic toxins [15].

It is well assessed that uremic toxin production is increased by a high protein/carbohydrates intake ratio, which fosters saccharolytic bacteria displacement in favour of proteolytic ones. While carbohydrates degradation releases mainly SCFA, which are known for their beneficial effects, protein metabolism leads to the production of a variety of compounds, among which the precursors of p-cresol and indoxyl sulphate, the main uremic toxins [40]. Moreover, an increasing body of evidence suggests that uremic toxin accumulation leads to an accelerated progression of CKD [41], and uremia is, in turn, responsible for a general status of gut dysbiosis [34] , in a vicious circle.

For the reasons mentioned above, the Mediterranean Diet with its abundant supply of complex carbohydrates and its low levels of animal proteins, represents an ideal dietary scheme for CKD patients, leading gut microbial metabolism towards a saccharolytic profile and favouring the shortening of colonic transit time, which is another factor positively correlated with bacterial toxins generation [15]. On the contrary, the Western diets, with their high protein/carbohydrates ratio, apart from being related with a variety of "western diseases", are the least recommended for CKD patients. Figure 1 summarize the complex relationship between these three actors: diet, microbiota and kidney, in the context of renal disease.

Indeed, several studies demonstrated the beneficial effects of the Mediterranean diet also in other pathological contexts, such as non-alcoholic fatty liver disease [42] and Crohn's disease [43]: these effects are believed to be mediated by gut microbiota.

The intriguing perspective to keep renal disease under control through a nutritional, non-pharmacological approach, slowing down the disease progression and attenuating the related comorbidities effects, is now far from an utopian idea. This is confirmed by studies in other disease models, such as immune-mediated pathologies, which demonstrate a quick and sharp effect of diet on microbiome and subsequently on the onset of the disease [44].

In our opinion, a desirable and innovative approach for CKD and HD patients should consider the association between a nutritional regimen based on the Mediterranean Diet model with symbiotic or probiotic/prebiotic formulations administration.

Probiotics, as defined by the Food and Agriculture Organization and the World Health Organization, are "live microorganisms which when administered in adequate amounts confer a health benefit on the host". They are constituted by the "beneficial bacteria" of the human gut microflora and can be administered orally to re-establish intestinal balance. Probiotic health-promoting action is supposed to be mediated by different mechanisms of action, including $\mathrm{pH}$ modulation, anti-bacterial compounds production, competition with pathogens [45].

Prebiotics are food indigestible molecules, usually oligosaccharides or complex saccharides, that are used as fermentation substrates and stimulate proliferation and activity of beneficial intestinal bacteria. Symbiotics are a formulation of either probiotics and prebiotics, with a synergic and integrated effect on gut flora balance and in health promotion.

In CKD context, the use of probiotic/prebiotic/symbiotic could be a potential interesting adjuvant treatment. This idea originates from the emerging concept of "enteric dialysis", i.e. the removal of uremic toxins by means of orally administered gut flora microorganisms. In this branch of research, many studies revealed interesting insights on the relationship between probiotic administration and uremia. An in vitro study showed that Lactobacillus delbrueckii, after cycles of exposures to urea-rich medium, is able to significantly reduce plasma urea concentrations, opening new horizons on the possibility of probiotic therapeutical use in CKD and HD patients [46]. In an animal model of CKD, two probiotic formulations revealed efficacy in survival prolongation, in blood urea-nitrogen lowering, and in slowingdown disease progression [47].

In humans, a Bifidobacterium longum (fermentative species) probiotic formulation in a gastro-resistant capsule, was administered to HD patients, which usually undergo a derangement in intestinal microbiota with a shift towards putrefactive bacteria, and was able 


\section{Kidney Blood Pressure Research}

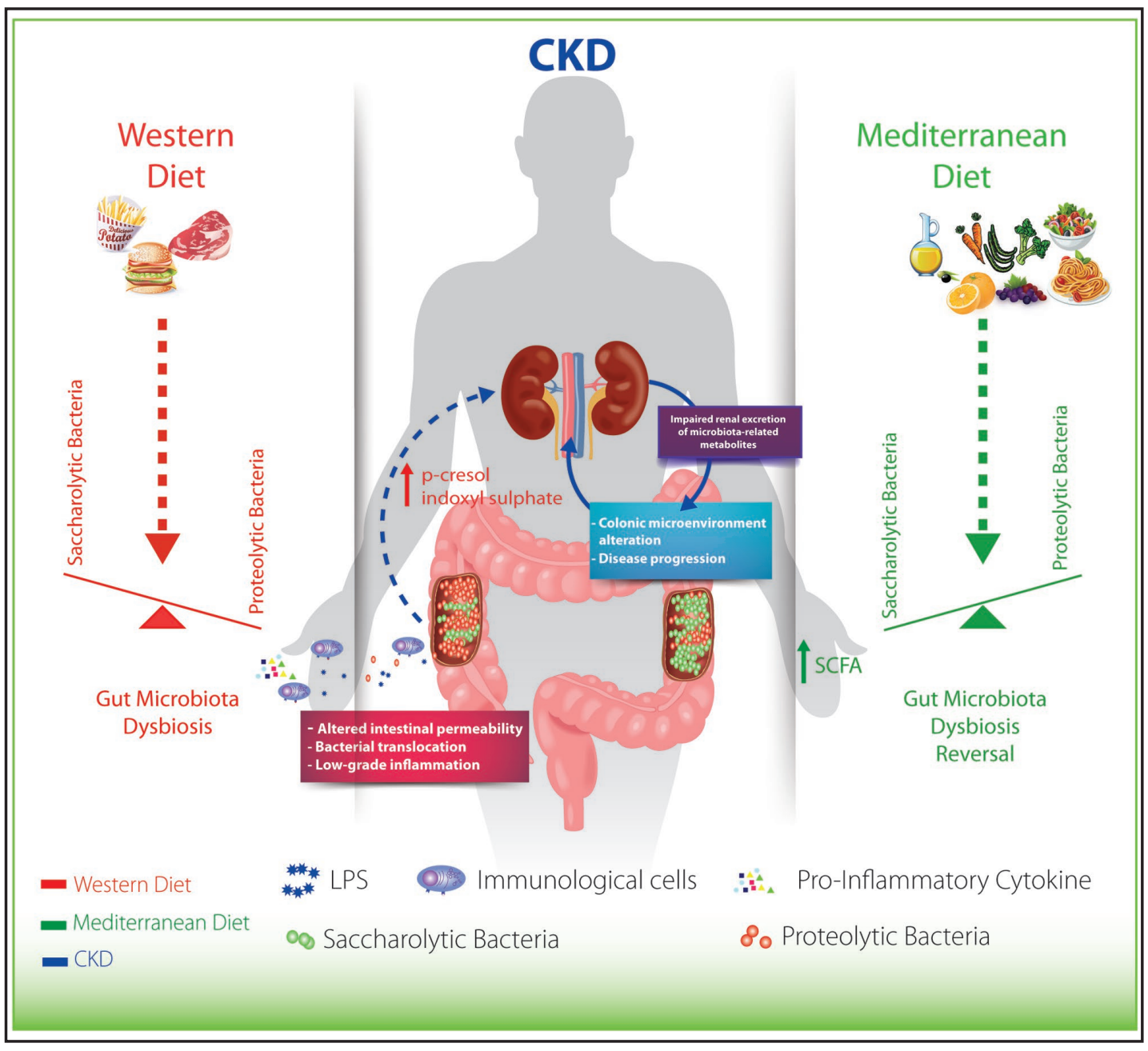

Fig. 1. The social network between diet, gut microbiota and kidney in CKD. In CKD, gut microbiota dysbiosis is present, leading to a prevalence of proteolytic species and to an increase in microbial uremic toxins (p-cresol and indoxyl sulphate). The impaired renal function, in turn, worsens the dysbiosis status and leads to an altered intestinal permeability and to low-grade inflammation. All this factors contribute to disease progression. In this context, a Western-style Diet contributes to the worsening of the dysbiosis, promoting the selective proliferation of proteolytic species. The Mediterranean Diet, by leading gut microbial metabolism towards a saccharolytic profile, can restore gut microbiota balance, ameliorating CKD conditions and slowing down disease progression.

to restore balance in gut microflora, to lower indoxyl sulphate, p-cresol, triglicerides and homocysteine (probably by means of vitamin B12 and folate produced by the own Bifidobacteria) serum levels [48].

Interestingly, Bifidobacteria administration reduces serum phosphorus levels, notoriously elevated in HD patients. This effect is probably due to the lowering of intestinal $\mathrm{pH}$ (because of acetic and lactic acids produced by B.), which increases intestinal calcium ionization. Ca++ in turn, acts as a natural phosphate binder, inhibiting $\mathrm{P}$ intestinal absorption [49]. Other clinical studies carried on humans confirmed the beneficial effects of a probiotic formulation, which reduced urea serum levels in stage 3 and 4 CKD patients [45, 47].

An alternative strategy aimed at re-establishing balance in microbiota could be the faecal transplantation, an emerging therapeutic practice mainly experimented in gastroin- 


\section{Kidney \\ Blood Pressure Research}

Kidney Blood Press Res 2014;39:114-123

\begin{tabular}{l|l}
\hline DOI: $10.1159 / 000355785$ & (C) 2014 S. Karger AG, Basel
\end{tabular}

Published onine: July 29, 2014

www.karger.com/kbr

Montemurno et al.: What Would You Like to Eat, Mr CKD Microbiota? A Mediterranean Diet, please!

testinal diseases, such as Clostridium Difficile Infection, ulcerative colitis, Crohn's disease ulcerative colitis, and irritable bowel syndrome [50]. The finding that microbiota dysbiosis is correlated also with other systemic pathologies, such as chronic renal disease, opens new perspectives on the potential application of faecal transplantation as an innovative therapy in nephropaties, although caution is needed and specific clinical trials need to be designed and carried on in order to assess the efficacy and safety of this approach [51].

Microbiota and microbiome have a great potentiality: they can be easily and readily manipulated in a non-invasive, natural way, which is food. There is a new increase of knowledge, acquired by high-throughput approaches to microbiota study, which is shedding a new light to the mechanisms by which food-microbiome interaction can modify risk factors [52]. This novel branch of research could lead, in the forthcoming future, to the design of highly personalised nutritional strategies, in order to define the most suitable dietary scheme for each individual.

This will give a rigorous and scientific basis to Hippocrates' statement, finally raising up diet at the degree of a real health elixir.

\section{Disclosure Statement}

The authors state that they do not have any conflicts and nothing to disclose.

\section{Acknowledgements}

The authors thank Chiara Di Giorgio for her editorial assistance and language revision of the manuscript.

\section{References}

1 Ruiz-Canela M, Martinez-Gonzalez MA: Lifestyle and dietary risk factors for peripheral artery disease. Circ J 2014;78:553-559.

-2 Mekki K, Bouzidi-Bekada N, Kaddous A, Bouchenak M: Mediterranean diet improves dyslipidemia and biomarkers in chronic renal failure patients. Food Funct 2010;1:110.

-3 Trichopoulou A, Kouris-Blazos A, Wahlqvist ML, Gnardellis C, Lagiou P, Polychronopoulos E, Vassilakou T, Lipworth L, Trichopoulos D: Diet and overall survival in elderly people. BMJ 1995;311:1457-1460.

4 Martín-Peláez S, Covas MI, Fitó M, Kušar A, Pravst I: Health effects of olive oil polyphenols: Recent advances and possibilities for the use of health claims. Mol Nutr Food Res 2013;57:760-771.

5 Ruiz-Canela M, Martinez-Gonzalez MA: Olive oil in the primary prevention of cardiovascular disease. Maturitas 2011;68:245-250.

6 Bouchenak M, Lamri-Senhadji M: Nutritional Quality of Legumes, and Their Role in Cardiometabolic Risk Prevention: A Review. J Med Food 2013;16:185-198.

7 Nordmann AJ, Suter-Zimmermann K, Bucher HC, Shai I, Tuttle KR, Estruch R, Briel M: Meta-Analysis Comparing Mediterranean to Low-Fat Diets for Modification of Cardiovascular Risk Factors. Am J Med 2011;124:841-851.e842.

-8 Zoetendal EG, de Vos WM: Effect of diet on the intestinal microbiota and its activity. Curr Opin Gastroenterol 2014;30:189-195.

-9 Ramezani A, Raj DS: The Gut Microbiome, Kidney Disease, and Targeted Interventions. J Am Soc Nephrol 2014;25:657-670.

10 Carroll IM, Threadgill DW, Threadgill DS: The gastrointestinal microbiome: a malleable, third genome of mammals. Mamm Genome 2009;20:395-403.

11 Sekirov I, Russell SL, Antunes LCM, Finlay BB: Gut Microbiota in Health and Disease. Physiol Rev 2010;90:859-904. 


\section{Kidney \\ Blood Pressure Research}

Kidney Blood Press Res 2014;39:114-123

\begin{tabular}{l|l}
\hline DOI: $10.1159 / 000355785$ & (C) 2014 S. Karger AG, Basel
\end{tabular}

Published onlıne: July 29, 2014

www.karger.com/kbr

Montemurno et al.: What Would You Like to Eat, Mr CKD Microbiota? A Mediterranean Diet, please!

12 Prakash S, Tomaro-Duchesneau C, Saha S, Cantor A: The gut microbiota and human health with an emphasis on the use of microencapsulated bacterial cells. J Biomed Biotechnol 2011;2011:981214.

13 Food and Agriculture Organization/World Health Organization: Carbohydrates in human nutrition: report of a Joint FAO/WHO expert consultation. FAO Food Nutr Paper 1998;66:1-140.

$>14$ Kau AL, Ahern PP, Griffin NW, Goodman AL, Gordon JI: Human nutrition, the gut microbiome and the immune system. Nature 2011;474:327-336.

-15 Evenepoel P, Meijers BKI, Bammens BRM, Verbeke K: Uremic toxins originating from colonic microbial metabolism. Kidney Int 2009;76:S12-S19.

16 Hylemon PB, Zhou H, Pandak WM, Ren S, Gil G, Dent P: Bile acids as regulatory molecules. J Lipid Res 2009;50:1509-1520.

17 Prawitt J, Abdelkarim M, Stroeve JHM, Popescu I, Duez H, Velagapudi VR, Dumont J, Bouchaert E, van Dijk TH, Lucas A, Dorchies E, Daoudi M, Lestavel S, Gonzalez FJ, Oresic M, Cariou B, Kuipers F, Caron S, Staels B: Farnesoid X Receptor Deficiency Improves Glucose Homeostasis in Mouse Models of Obesity. Diabetes 2011;60:1861-1871.

18 Scott KP, Gratz SW, Sheridan PO, Flint HJ, Duncan SH: The influence of diet on the gut microbiota. Pharmacol Res 2013;69:52-60.

19 Tremaroli V, Backhed F: Functional interactions between the gut microbiota and host metabolism. Nature 2012;489:242-249.

-20 Grenham S, Clarke G, Cryan JF, Dinan TG: Brain-gut-microbe communication in health and disease. Front Physiol 2011;2:94.

-21 Lozupone CA, Stombaugh JI, Gordon JI, Jansson JK, Knight R: Diversity, stability and resilience of the human gut microbiota. Nature 2012;489:220-230.

-22 Harmsen HJM, Wildeboer-Veloo ACM, Grijpstra J, Knol J, Degener JE, Welling GW: Development of 16S rRNA-Based Probes for theCoriobacterium Group and the Atopobium Cluster and Their Application for Enumeration of Coriobacteriaceaein Human Feces from Volunteers of Different Age Groups. Appl Environ Microbiol 2000;66:4523-4527.

23 Sokol H, Lepage P, Seksik P, Dore J, Marteau P: Temperature gradient gel electrophoresis of fecal 16S rRNA reveals active Escherichia coli in the microbiota of patients with ulcerative colitis. J Clin Microbiol 2006;44:3172-3177.

24 Wu GD, Chen J, Hoffmann C, Bittinger K, Chen Y-Y, Keilbaugh SA, Bewtra M, Knights D, Walters WA, Knight R, Sinha R, Gilroy E, Gupta K, Baldassano R, Nessel L, Li H, Bushman FD, Lewis JD: Linking Long-Term Dietary Patterns with Gut Microbial Enterotypes. Science 2011;334:105-108.

-25 Zimmer J, Lange B, Frick JS, Sauer H, Zimmermann K, Schwiertz A, Rusch K, Klosterhalfen S, Enck P: A vegan or vegetarian diet substantially alters the human colonic faecal microbiota. Eur J Clin Nutr 2012;66:53-60.

-26 David LA, Maurice CF, Carmody RN, Gootenberg DB, Button JE, Wolfe BE, Ling AV, Devlin AS, Varma Y, Fischbach MA, Biddinger SB, Dutton RJ, Turnbaugh PJ: Diet rapidly and reproducibly alters the human gut microbiome. Nature 2014;505:559-563.

-27 Vaziri ND, Yuan J, Rahimi A, Ni Z, Said H, Subramanian VS: Disintegration of colonic epithelial tight junction in uremia: a likely cause of CKD-associated inflammation. Nephrol Dial Transplant 2012;27:2686-2693.

28 Vipperla K, O‘Keefe SJ: The Microbiota and Its Metabolites in Colonic Mucosal Health and Cancer Risk. Nutr Clin Pract 2012;27:624-635.

29 Zhang Q-L, Rothenbacher D: Prevalence of chronic kidney disease in population-based studies: Systematic review. BMC Public Health 2008;8:117.

-30 Filiopoulos V, Hadjiyannakos D, Takouli L, Metaxaki P, Sideris V, Vlassopoulos D: Inflammation and oxidative stress in end-stage renal disease patients treated with hemodialysis or peritoneal dialysis. Int J Artif Organs 2009;32:872-882.

-31 Tziomalos K, Ganotakis ES, Gazi IF, Nair DR, Mikhailidis DP: Kidney function and estimated vascular risk in patients with primary dyslipidemia. Open Cardiovasc Med J 2009;3:57-68.

-32 McCarthy DD, Kujawa J, Wilson C, Papandile A, Poreci U, Porfilio EA, Ward L, Lawson MA, Macpherson AJ, McCoy KD, Pei Y, Novak L, Lee JY, Julian BA, Novak J, Ranger A, Gommerman JL, Browning JL: Mice overexpressing BAFF develop a commensal flora-dependent, IgA-associated nephropathy. J Clin Invest 2011;121:3991-4002. 


\section{Kidney \\ Blood Pressure Research}

Kidney Blood Press Res 2014;39:114-123

\begin{tabular}{l|l}
\hline DOI: $10.1159 / 000355785$ & (C) 2014 S. Karger AG, Basel
\end{tabular}

Published onine: July 29, 2014

www.karger.com/kbr

Montemurno et al.: What Would You Like to Eat, Mr CKD Microbiota? A Mediterranean Diet, please!

33 Neish AS: Microbes in gastrointestinal health and disease. Gastroenterology 2009;136:65-80.

-34 Vaziri ND, Wong J, Pahl M, Piceno YM, Yuan J, DeSantis TZ, Ni ZM, Nguyen TH, Andersen GL: Chronic kidney disease alters intestinal microbial flora. Kidney International 2013;83:308-315.

35 Joyce SA, Gahan CG: The gut microbiota and the metabolic health of the host. Curr Opin Gastroenterol 2014;30:120-127.

-36 Kalantar-Zadeh K, Kopple JD, Deepak S, Block D, Block G: Food intake characteristics of hemodialysis patients as obtained by food frequency questionnaire. J Ren Nutr 2002;12:17-31.

-37 Poesen R, Meijers B, Evenepoel P: The colon: an overlooked site for therapeutics in dialysis patients. Semin Dial 2013;26:323-332.

38 Miyazaki T, Ise M, Seo H, Niwa T: Indoxyl sulfate increases the gene expressions of TGF-beta 1, TIMP-1 and pro-alpha 1(I) collagen in uremic rat kidneys. Kidney Int 1997;52:S15-S22.

39 Vitetta L, Gobe G: Uremia and chronic kidney disease: The role of the gut microflora and therapies with pro- and prebiotics. Molec Nutr Food Res 2013;57:824-832.

40 Bammens B, Verbeke K, Vanrenterghem Y, Evenepoel P: Evidence for impaired assimilation of protein in chronic renal failure. Kidney Int 2003;64:2196-2203.

41 Meyer TW, Hostetter TH: Uremic solutes from colon microbes. Kidney Int 2012;81:949-954.

42 Vos MB: Nutrition, nonalcoholic fatty liver disease and the microbiome: recent progress in the field. Curr Opin Lipidol 2014;25:61-66.

43 Marlow G, Ellett S, Ferguson IR, Zhu S, Karunasinghe N, Jesuthasan AC, Han DY, Fraser AG, Ferguson LR: Transcriptomics to study the effect of a Mediterranean-inspired diet on inflammation in Crohn's disease patients. Hum Genomics 2013;7:24.

44 Ooi JH, Waddell A, Lin YD, Albert I, Rust LT, Holden V, Cantorna MT: Dominant effects of the diet on the microbiome and the local and systemic immune response in mice. Plos One 2014;9:e86366.

-45 Ranganathan N, Ranganathan P, Friedman EA, Joseph A, Delano B, Goldfarb DS, Tam P, Rao AV, Anteyi E, Musso CG: Pilot study of probiotic dietary supplementation for promoting healthy kidney function in patients with chronic kidney disease. Adv Ther 2010;27:634-647.

46 Chow KM, Liu ZC, Prakash S, Chang TM: Free and microencapsulated Lactobacillus and effects of metabolic induction on urea removal. Artif Cells Blood Substit Immobil Biotechnol 2003;31:425-434.

47 Ranganathan N, Patel B, Ranganathan P, Marczely J, Dheer R, Chordia T, Dunn SR, Friedman EA: Probiotic amelioration of azotemia in 5/6th nephrectomized Sprague-Dawley rats. ScientificWorldJournal 2005;5:652-660.

48 Taki K, Takayama F, Niwa T: Beneficial effects of Bifidobacteria in a gastroresistant seamless capsule on hyperhomocysteinemia in hemodialysis patients. J Ren Nutr 2005;15:77-80.

49 Ogawa T, Shimada M, Nagano N, Ito K, Ando T, Shimomura Y, Ando Y, Otsuka K: Oral administration of Bifidobacterium longum in a gastro-resistant seamless capsule decreases serum phosphate levels in patients receiving haemodialysis. Clin Kidney J 2012;5:373-374.

-50 Borody TJ, Brandt LJ, Paramsothy S: Therapeutic faecal microbiota transplantation: current status and future developments. Curr Opin Gastroenterol 2014;30:97-105.

-51 van Nood E, Speelman P, Nieuwdorp M, Keller J: Fecal microbiota transplantation: facts and controversies. Curr Opin Gastroenterol 2014;30:34-39.

52 Kinross J, Li JV, Muirhead LJ, Nicholson J: Nutritional modulation of the metabonome: applications of metabolic phenotyping in translational nutritional research. Curr Opin Gastroenterol 2014;30:196-207. 